OPEN ACCESS

Edited by:

Meryem Yilmaz Soylu,

University of Nebraska-Lincoln,

United States

Reviewed by:

Francisco D. Fernández-Martín,

University of Granada, Spain

Kasey Orvidas,

North Carolina State University,

United States

Kate Xu,

Open University of the Netherlands,

Netherlands

*Correspondence:

Christopher A. Kearney

chris.kearney@unlv.edu

Specialty section:

This article was submitted to

Educational Psychology,

a section of the journal

Frontiers in Psychology

Received: 24 April 2020

Accepted: 24 July 2020

Published: 14 August 2020

Citation:

Kearney CA, Sanmartín $R$ and Gonzálvez C (2020) The School

Climate and Academic Mindset

Inventory (SCAMI): Confirmatory Factor Analysis and Invariance Across

Demographic Groups.

Front. Psychol. 11:2061.

doi: 10.3389/fpsyg.2020.02061

\section{The School Climate and Academic Mindset Inventory (SCAMI): Confirmatory Factor Analysis and Invariance Across Demographic Groups}

\author{
Christopher A. Kearney ${ }^{1 *}$, Ricardo Sanmartín² and Carolina Gonzálvez² \\ 'Department of Psychology, University of Nevada, Las Vegas, Las Vegas, NV, United States, ${ }^{2}$ Department of Developmental
} Psychology and Teaching, University of Alicante, Alicante, Spain

School climate is a multidimensional construct of the quality of a student's academic environment, often subsuming dimensions such as safety, instructional practices, social relationships, school facilities, and school connectedness. Positive school climate has beneficial effects on a wide range of adjustment variables in youth, including academic achievement, mental health, school attendance and graduation, and school-based behavior. Studies regarding school climate assessment have burgeoned in recent years but remain marked by limited sample sizes, narrow developmental levels, restricted items, unclear psychometric strength across multiple demographic groups, and lack of integration with key student education contextual factors such as academic mindset and social emotional learning. The present study evaluated a comprehensive measure of aspects of school climate, academic mindset, and social emotional learning in a sample of 105,379 diverse students ( $M$ age $=13.47$ years; $S D=2.47$ ). The 9-factor structure of the School Climate and Academic Mindset Inventory was supported via confirmatory factor analysis. A trimmed model displayed adequate goodness-of-fit for males and females, younger age groups, and European American, biracial/multiracial, Hispanic, Native American, and Native Hawaiian/Pacific Islander students. The trimmed model was slightly less strong for older age groups as well as for African American and Asian American students. The scale may be useful for assessing school climate interventions, longitudinal climate patterns, and school-based algorithms of future performance, though additional validation of the scale remains necessary.

Keywords: school climate, school climate and academic mindset inventory, confirmatory factor analysis, academic mindset, social emotional learning

\section{INTRODUCTION}

School climate is a multidimensional construct of the "quality and character of school life" that reflects "norms, goals, values, interpersonal relationships, teaching and learning practices, and organizational structures" in a youth-based academic environment (Cohen et al., 2009; Thapa and Cohen, 2017, pp. 303-304). Key dimensions of school climate include safety, instructional practices, 
social relationships, school facilities, and school connectedness (Zullig et al., 2010). Other, related dimensions of school climate include community, equity, institutional or academic environment, leadership, and shared beliefs (Uline et al., 2010; Wang and Degol, 2016).

Dimensions of school climate have been further explicated in the literature. Safety refers to actual and perceived degree of relational aggression as well as respect for others, supportive environments, and clear rules and norms (Goldstein et al., 2008; Capp et al., 2020). Teaching and learning practices refer to quality of instruction, social emotional learning, and support for academic achievement (Gage et al., 2016). Social relationships refer to parent involvement, supportive relationships with important others such as peers and teachers at school, and respect for diversity (Bradshaw et al., 2014b; Gage et al., 2014). School facilities refer to the condition of the physical environment of an academic setting as well as availability of resources and supplies (Gislason, 2010). School connectedness refers to student affective attachment to the academic community, commitment to social and academic goals, and involvement in social and academic activities (García-Moya et al., 2019). Several of these dimensions overlap in definition and scope, most notably degree of support from the academic environment (Thapa et al., 2013; McMillan et al., 2017).

School climate has been linked to improved child and adolescent socioemotional and academic adjustment in many ways. Positive school climate has been associated with enhanced academic achievement, particularly among students from lower socioeconomic backgrounds (Berkowitz et al., 2017; Maxwell et al., 2017). In addition, positive or authoritative school climate is associated with various mental health benefits that include increased self-esteem, psychosocial wellbeing, and perceived quality of life as well as less depression, suicidal thoughts and behavior, substance use, and psychiatric problems (Thapa et al., 2013; Cornell and Huang, 2016; Aldridge and McChesney, 2018; Zullig et al., 2018). Positive school climate is also linked to academic behavioral outcomes such as less absenteeism, school dropout, suspensions, disciplinary referrals, and bullying and other violent school-based incidents (Kutsyuruba et al., 2015; Hendron and Kearney, 2016; Jia et al., 2016; Reaves et al., 2018). More broadly, positive school climate relates to enhanced teacher satisfaction, retention, efficacy, and productivity as well as less burnout (Berkowitz et al., 2017).

School climate enhancement has thus become a central aspect of broad-based school improvement strategies. Such efforts prominently include, for example, Positive Behavioral Interventions and Supports (PBIS), a systemic intervention to promote a positive school environment that includes appropriate student and teacher behavior (Sugai and Horner, 2002). Key aspects of PBIS include clearly articulated behavioral expectations, student incentives, positive student-teacher interactions, effective classroom management, and empirically based decision making (Bradshaw et al., 2014a). Efforts to improve school climate are typically integrated into multi-tiered systems of support models that focus in part on primary prevention practices to promote adaptive behavior and to deter maladaptive behavior (Lewis et al., 2017). PBIS implemented with fidelity relates to improvements in academic performance, bullying, office discipline referrals, social emotional competencies, and student suspensions and expulsions (Bradshaw et al., 2010; Horner and Sugai, 2015; Freeman et al., 2016).

The importance of school climate to child and adolescent adjustment as well as to overall academic and behavioral outcomes mandates the need for comprehensive and psychometrically strong assessment measures for this construct, particularly for schools (Lindstrom Johnson et al., 2019). A full review of school climate assessments is beyond the scope of this article (for reviews, see Ramelow et al., 2015; Olsen et al., 2018). These measures focus primarily on various dimensions of school climate described earlier in addition to ancillary variables such as substance use, school-community relations, and school identification (e.g., Lee et al., 2017). Substantial variability exists across the measures with respect to school climate domains and how these domains are labeled (Shukla et al., 2019).

Despite the availability of instruments to measure school climate, researchers have noted shortcomings with respect to many of these measures and their associated psychometric properties (Ramelow et al., 2015; Olsen et al., 2018). First, many measures in this area are not particularly comprehensive, instead focusing on limited numbers of constructs and items related only to safety, student-teacher relationships, and connectedness (Berkowitz et al., 2017). Second, psychometric support for most school climate assessments is limited and is often based on restricted sample sizes and developmental levels (Wang and Degol, 2016). Third, important student-based contextual variables related to school climate are often neglected in these measurements (Konold, 2018). Examples include key academic mindset and social emotional learning competencies utilized by students in their academic endeavors (Rattan et al., 2015; Lawson et al., 2019). Theories of optimal school performance in children often integrate student-based contextual factors with school climate (Lee and Shute, 2010; Rudasill et al., 2018).

Academic mindsets refer to "beliefs, attitudes, or ways of perceiving oneself in relation to learning and intellectual work that support academic performance" (Farrington et al., 2012, p. 28). Such intrinsic motivational or non-cognitive factors, including academic tenacity or self-efficacy, relate closely to improved academic achievement across many demographic groups (Yeager and Dweck, 2012; Dweck et al., 2014). Organizational learning variables that can include a positive school climate correlate significantly with a growth mindset culture among students (Hanson et al., 2016). Mechanisms for this relationship may include enhanced student sense of contextual fairness as well as solidarity or belongingness at school, incentives for academic performance, trust in authorities, and transmission of mindset beliefs by teachers (Thomas et al., 2019).

Social emotional learning competencies, sometimes integrated with the teaching and learning practices domain of school climate, refer broadly to skills regarding self-awareness, selfmanagement, social awareness, relationships, and responsible decision-making (Durlak et al., 2015). Social emotional learning practices can help produce adaptive academic mindsets via (1) explicit instruction in interpersonal, emotional, and cognitive 
skills, (2) ample school-based opportunities to use these skills, and (3) effective classroom management and discipline approaches (Darling-Hammond and Cook-Harvey, 2018). Efforts to enhance school climate often include social-emotional learning practices to promote safe contexts to develop these skills and to boost student engagement (Corcoran et al., 2018).

The aim of the present study was to evaluate a comprehensive measure of aspects of school climate, academic mindset, and social emotional learning in a very large sample of diverse students. The study was designed in part to help address drawbacks associated with extant measures in this area such as restricted comprehensiveness and sample size, limited psychometric strength across multiple demographic groups, and lack of integration with key contextual factors related to student learning. Specifically, the present study examined the adjustment and reliability of a districtwide 9-factor, 66-item measure of school climate and academic mindset (School Climate and Academic Mindset Inventory; SCAMI) among tens of thousands of elementary, middle, and high school students. The primary hypothesis was that the original 9-factor model representing these constructs (i.e., parent involvement and support, academic mindset, social emotional learning, safety, physical safety, bullying, physical environment and resources, respect for diversity, and perceptions of school performance) would be supported via confirmatory factor analysis. In addition, factorial invariance across multiple demographic groups was expected. Model trimming was implemented as needed.

\section{MATERIALS AND METHODS}

\section{Participants}

Participants included 4th-12th grade students $(n=105,379)$ in a large urban school district in the United States. Participants were slightly more female (50.1\%), aged 921 years $(M=13.47 ; S D=2.47)$, and Hispanic/Latino $(45.5 \%)$, European American (27.7\%), African American (10.3\%), Asian (8.2\%), biracial/multiracial (6.3\%), Native Hawaiian/Pacific Islander (1.6\%), and American Indian/Alaska Native (0.4\%). Distribution by age group follows: 9-11 years $(39,860), 12-$ 14 years $(27,116), 15-16$ years $(21,590), 17-18$ years $(16,228)$, and $>18$ years (585). Participants voluntarily completed an online survey of the measure described next during the spring semester of the 2016-2017 academic year. The survey was posted publicly by the school district and via social media, but the largest contingent of students completed the measure at their school. Each school was encouraged to survey $75 \%$ of their population, but the overall response rate is unknown.

\section{Measure and Data Analyses}

Original subscales and associated items are in Table 1. Subscales $(n=9)$ included Parent Involvement and Support, Academic Mindset, Social Emotional Learning, Safety, Physical Safety, Bullying, Physical Environment and Resources, Respect for Diversity, and Perceptions of School Performance. Items were derived by the school district via original development, a state department of education, and the University of Chicago Consortium on School Research (academic mindset questions). Items are scored in variable fashion (Table 1).

The subscales had different Likert-type scales, so raw data were lineally transformed to obtain scores on a 0 100 scale (see Vilagut et al., 2005). Items were reversedscored as needed. Confirmatory factor analyses (CFA) were then performed to analyze models that could be adjusted to the data: 0-factor model, 1-factor model, original 9-factor model (with correlated and uncorrelated factors), a trimmed 9-factor model (with correlated and uncorrelated factors), and a trimmed 9-factor model with a second-order factor (with correlated and uncorrelated factors). A trimmed 9-factor model was obtained by analyzing item saturation in each of the factors, keeping the theoretical meaning of the items inside the respective factors and the modification indices (Leung et al., 2013; Gonzálvez et al., 2016; Gómez-Núñez et al., 2020). Mardia's coefficient of the total sample was above the 5 points established as multivariate normality in the data $(1,122.76)$, so the Robust Maximum Likelihood (RML) and Satorra-Bentler $\chi^{2}$ scaled (S-B $\chi^{2}$ ) were applied (Bentler, 2005). To identify extreme cases with respect to multivariate kurtosis, the method that was employed was the analysis of the five cases automatically provided by EQS that contribute most to the normalized multivariate kurtosis estimate. The criterion used was the comparison between the estimate presented for one case relative to the estimate of the other four cases. This method was implemented until the five estimates of the final sample were included in the same range of values and none was distinctively different from the others (Byrne, 2008).

Four goodness-of-fit indices were examined for the models: robust root mean square error of approximation (R-RMSEA), standardized root mean square residual (SRMR), robust comparative fit index (R-CFI), and Tucker Lewis index (TLI). Acceptable goodness-of-fit in this study was defined as rounded SRMR and R-RMSEA values of $<0.08$ and R-CFI and TLI values of 0.90+ (Hu and Bentler, 1999; Brown, 2006). In addition, the upper end of the R-RMSEA 90\% confidence interval should be $<0.10$ (Kline, 2005). Subscale reliability of the best-fitting model was evaluated via Cronbach's alpha and Omega coefficients (McDonald, 1999).

Multigroup confirmatory factor analyses were performed to test factorial invariance of the chosen model (configural, measurement, and structural invariance) across gender, age group $(9-11,12-14,15-16,17-18,18+$ years $)$ and ethnic group (Hispanic/Latino, European American, African American, Asian, Biracial/Multiracial, Native Hawaiian/Pacific Islander, and American Indian/Alaska Native). Mardia's coefficients were elevated, so the $\mathrm{S}-\mathrm{B} \chi^{2}$ and the robust indices mentioned above were used to include certain groups in the invariance analyses and determine the adequacy of the nested models that are part of the invariance analyses. An invariance criterion $(\Delta \mathrm{R}$ CFI $>-0.01$ ) was also utilized to accept nested models (Byrne, 2008). Statistical analyses were calculated using SPSS, Amos 23, and EQS 6.1. 
TABLE 1 | School Climate and Academic Mindset Inventory items (original model).

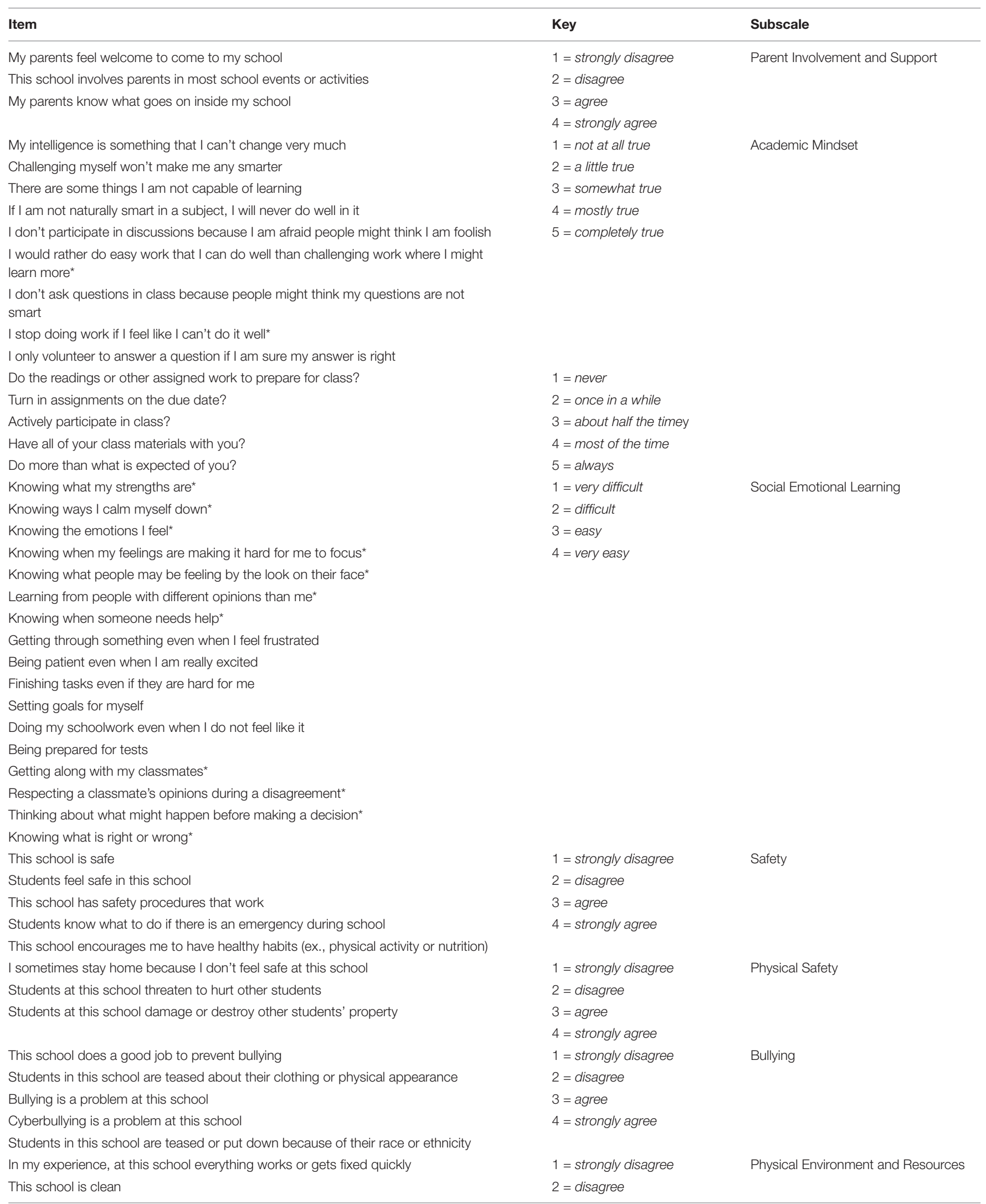


TABLE 1 | Continued

\begin{tabular}{|c|c|c|}
\hline Item & Key & Subscale \\
\hline The heating and air conditioning work well at this school & $3=$ agree & \\
\hline The technology (computers, iPads, mobile devices, etc.) works well at this school & 4 = strongly agree & \\
\hline \multicolumn{3}{|l|}{ The equipment and facilities at this school work well } \\
\hline $\begin{array}{l}\text { School staff treat students with respect, regardless of differences like race, ethnicity, gender, or } \\
\text { disability }\end{array}$ & $\begin{array}{l}1=\text { strongly disagree } \\
2=\text { disagree }\end{array}$ & Respect for Diversity \\
\hline This school encourages an appreciation of student diversity and respect for each other & $3=$ agree & \\
\hline $\begin{array}{l}\text { School staff encourages all students to take challenging courses no matter their race, ethnicity, } \\
\text { gender, or disability }\end{array}$ & 4 = strongly agree & \\
\hline \multicolumn{3}{|l|}{$\begin{array}{l}\text { Student treat other students with respect, regardless of differences like race, ethnicity, gender, or } \\
\text { disability }\end{array}$} \\
\hline \multicolumn{3}{|l|}{ My school encourages me to be courteous and respectful toward others } \\
\hline At my school, my teachers tell me how I am doing in my classes & 1 = strongly disagree & Perceptions of School Performance \\
\hline This school promotes academic success for all students & 2 = disagree & \\
\hline I am learning with technology such as computers, mobile devices and the Internet at this school & $3=$ agree & \\
\hline | like my school* & 4 = strongly agree & \\
\hline \multicolumn{3}{|l|}{ I am getting a good education at this school } \\
\hline \multicolumn{3}{|l|}{ Help is available at this school if I have trouble with my schoolwork } \\
\hline \multicolumn{3}{|l|}{ Teachers understand my problems } \\
\hline My teachers care about me ${ }^{\star}$ & & \\
\hline If I am absent, there is a teacher or some other adult at school that will notice my absence & & \\
\hline
\end{tabular}

${ }^{*}$ Removed items in trimmed model.

\section{RESULTS}

\section{Confirmatory Factor Analyses and Reliability}

Results from the CFAs are in Table 3. The 0-factor, 1-factor, and original 9-factor model with and without correlated factors did not meet criteria for adequate goodness-of-fit. Model trimming then consisted of removing 15 items whose factor loadings were $<0.40$ (noted in Table 1). These items included 2 from academic mindset, 11 from social emotional learning, and 2 from perceptions of school environment. Errors were correlated to improve model fit. No items were removed from the other subscales, and no items were moved from one subscale to another (Table 2). Removal of these 15 items produced a trimmed 9-factor 51-item model for the SCAMI with and without correlated factors that was not supported by all goodness-offit indices. A new trimmed 9-factor model dividing factor 2 (academic mindset) into a second-order factor was proposed (Table 3). The trimmed 9-factor model with a second-order factor with correlated factors met criteria for adequate goodnessof-fit (R-RMSEA $=0.034,90 \%$ confidence interval: $0.34-0.34$; SRMR $=0.047$; R-CFI $=0.908 ;$ TLI $=0.901)$.

Factor loadings of the trimmed 9-factor model with one second-order factor with correlated factors ranged from 0.43-0.83. Internal consistency coefficients (Cronbach's alpha/Omega/Composite reliability/Average Variance Extracted) were calculated for each subscale: Parent involvement and Support (0.61/0.61/0.61/0.35), Academic Mindset (0.75/0.87/0.87/0.37), Social Emotional Learning $(0.75 / 0.76 / 0.76 / 0.35)$, Safety $(0.84 / 0.83 / 0.83 / 0.50)$, Physical Safety (0.72/0.74/0.74/0.50), Bullying (0.81/0.80/0.80/0.45),
Physical Environment and Resources (0.78/0.78/0.78/0.41), Respect for Diversity $(0.79 / 0.80 / 0.80 / 0.45)$, and Perceptions of School Performance $(0.83 / 0.84 / 0.84 / 0.42)$.

\section{Factorial Invariance Across Demographic Groups}

Factorial invariance of the trimmed 9-factor model with one second-order factor was examined across several demographic groups. A baseline model (Model 0) without constraints was initially established; factor loadings of first order (Model 1) and second order (Model 2) models were then imposed to obtain metric invariance. In addition, intercept constraints were added to Model 2 and the strong or scalar invariance (Model 3) was obtained. Factor loadings (first and second order), intercepts, and variances and covariances of errors were constrained to test strict invariance (Model 4). Finally, covariances of the factors were constrained in Model 2 to test structural invariance (Model 5).

Regarding invariance across gender, the trimmed model displayed adequate goodness-of-fit criteria for males and females (TLI and R-CFI > 0.90; R-RMSEA < 0.05; SRMR < 0.08; $\Delta \mathrm{R}$-CFI values $>-0.01$ ) (Table 4). Measurement and structural invariance were thus confirmed (adequate goodnessof-fit indexes values and $\triangle \mathrm{R}-\mathrm{CFI}>-0.01$ for all tested models). Regarding invariance across age, the trimmed model displayed adequate goodness-of-fit criteria for younger age groups: 9-11 years and 12-14 years (TLI and R-CFI > 0.90; R-RMSEA < 0.05; SRMR < 0.08) (Table 3) but less so for older age groups: $15-16$ years ( $\mathrm{R}-\mathrm{RMSEA}=0.037,90 \%$ confidence interval: $0.37-0.37$; SRMR $=0.049$; R-CFI = 0.894; $\mathrm{TLI}=0.886$ ); 17-18 years (R-RMSEA $=0.040,90 \%$ confidence interval: 0.39-0.40; $\mathrm{SRMR}=0.054 ; \mathrm{R}-\mathrm{CFI}=0.884 ; \mathrm{TLI}=0.875$; 
TABLE 2 | School Climate and Academic Mindset Inventory items (trimmed model).

\begin{tabular}{|c|c|c|}
\hline Item & Key & Subscale \\
\hline My parents feel welcome to come to my school & 1 = strongly disagree & Parent Involvement and Support \\
\hline This school involves parents in most school events or activities & 2 = disagree & \\
\hline \multirow[t]{2}{*}{ My parents know what goes on inside my school } & 3 = agree & \\
\hline & 4 = strongly agree & \\
\hline My intelligence is something that I can't change very much & $1=$ not at all true & Academic Mindset \\
\hline Challenging myself won't make me any smarter & 2 = a little true & \\
\hline There are some things I am not capable of learning & $3=$ somewhat true & \\
\hline If I am not naturally smart in a subject, I will never do well in it & $4=$ mostly true & \\
\hline I don't participate in discussions because I am afraid people might think I am foolish & $5=$ completely true & \\
\hline \multicolumn{3}{|l|}{ I don't ask questions in class because people might think my questions are not smart } \\
\hline \multicolumn{3}{|l|}{ I only volunteer to answer a question if I am sure my answer is right } \\
\hline Do the readings or other assigned work to prepare for class? & $1=$ never & \\
\hline Turn in assignments on the due date? & $2=$ once in a while & \\
\hline Actively participate in class? & $3=$ about half the time & \\
\hline Have all of your class materials with you? & $4=$ most of the time & \\
\hline Do more than what is expected of you? & $5=$ always & \\
\hline Getting through something even when I feel frustrated & 1 = very difficult & Social Emotional Learning \\
\hline Being patient even when I am really excited & $2=$ difficult & \\
\hline Finishing tasks even if they are hard for me & $3=$ easy & \\
\hline Setting goals for myself & 4 = very easy & \\
\hline \multicolumn{3}{|l|}{ Doing my schoolwork even when I do not feel like it } \\
\hline \multicolumn{3}{|l|}{ Being prepared for tests } \\
\hline This school is safe & 1 = strongly disagree & Safety \\
\hline Students feel safe in this school & 2 = disagree & \\
\hline This school has safety procedures that work & 3 = agree & \\
\hline Students know what to do if there is an emergency during school & 4 = strongly agree & \\
\hline \multicolumn{3}{|l|}{ This school encourages me to have healthy habits (ex., physical activity or nutrition) } \\
\hline I sometimes stay home because I don't feel safe at this school & 1 = strongly disagree & Physical Safety \\
\hline Students at this school threaten to hurt other students & 2 = disagree & \\
\hline \multirow[t]{2}{*}{ Students at this school damage or destroy other students' property } & $3=$ agree & \\
\hline & 4 = strongly agree & \\
\hline This school does a good job to prevent bullying & 1 = strongly disagree & Bullying \\
\hline Students in this school are teased about their clothing or physical appearance & 2 = disagree & \\
\hline Bullying is a problem at this school & $3=$ agree & \\
\hline Cyberbullying is a problem at this school & 4 = strongly agree & \\
\hline \multicolumn{3}{|l|}{ Students in this school are teased or put down because of their race or ethnicity } \\
\hline In my experience, at this school everything works or gets fixed quickly & 1 = strongly disagree & Physical Environment and Resources \\
\hline This school is clean & 2 = disagree & \\
\hline The heating and air conditioning work well at this school & $3=$ agree & \\
\hline The technology (computers, iPads, mobile devices, etc.) works well at this school & 4 = strongly agree & \\
\hline \multicolumn{3}{|l|}{ The equipment and facilities at this school work well } \\
\hline School staff treat students with respect, regardless of differences like race, ethnicity, & 1 = strongly disagree & Respect for Diversity \\
\hline gender, or disability & 2 = disagree & \\
\hline This school encourages an appreciation of student diversity and respect for each other & $3=$ agree & \\
\hline $\begin{array}{l}\text { School staff encourages all students to take challenging courses no matter their race, } \\
\text { ethnicity, gender, or disability }\end{array}$ & 4 = strongly agree & \\
\hline \multicolumn{3}{|l|}{$\begin{array}{l}\text { Student treat other students with respect, regardless of differences like race, ethnicity, } \\
\text { gender, or disability }\end{array}$} \\
\hline \multicolumn{3}{|l|}{ My school encourages me to be courteous and respectful toward others } \\
\hline At my school, my teachers tell me how I am doing in my classes & 1 = strongly disagree & Perceptions of School Performance \\
\hline This school promotes academic success for all students & 2 = disagree & \\
\hline $\begin{array}{l}\text { I am learning with technology such as computers, mobile devices and the Internet at } \\
\text { this school }\end{array}$ & $3=$ agree & \\
\hline
\end{tabular}

(Continued) 
TABLE 2 | Continued

\begin{tabular}{|c|c|c|c|c|c|c|}
\hline Item & \multicolumn{2}{|c|}{ Key } & \multicolumn{2}{|c|}{ Subscale } & & \\
\hline I am getting a good education at this school & \multicolumn{3}{|c|}{4 = strongly agree } & & & \\
\hline \multicolumn{7}{|l|}{ Help is available at this school if I have trouble with my schoolwork } \\
\hline \multicolumn{7}{|l|}{ Teachers understand my problems } \\
\hline \multicolumn{7}{|l|}{ If I am absent, there is a teacher or some other adult at school that will notice my absence } \\
\hline & S-B $x^{2}$ & df & R-RMSEA $90 \%$ Cl & SRMR & R-CFI & TLI \\
\hline 0-factor model & 2051321.19 & 2145 & $0.095[0.095,0.095]$ & 0.225 & 0.000 & 0.000 \\
\hline 1-factor model & 841569.57 & 2079 & $0.062[0.062,0.062]$ & 0.079 & 0.590 & 0.577 \\
\hline Original 9-factor model with non-correlated factors & 706350.10 & 2079 & $0.057[0.057,0.057]$ & 0.193 & 0.656 & 0.645 \\
\hline Original 9-factor model with correlated factors & 339922.74 & 2043 & $0.040[0.040,0.040]$ & 0.056 & 0.835 & 0.827 \\
\hline Trimmed 9-factor model with non-correlated factors & 585501.18 & 1221 & $0.067[0.067,0.068]$ & 0.214 & 0.634 & 0.617 \\
\hline Trimmed 9-factor model with correlated factors & 221087.08 & 1185 & $0.042[0.042,0.042]$ & 0.058 & 0.862 & 0.852 \\
\hline Trimmed 9-factor model with one second-order factor with non-correlated factors & 515599.04 & 1218 & $0.063[0.063,0.063]$ & 0.212 & 0.678 & 0.662 \\
\hline Trimmed 9-factor model with one second-order factor with correlated factors & 148025.13 & 1182 & $0.034[0.034,0.034]$ & 0.047 & 0.908 & 0.901 \\
\hline
\end{tabular}

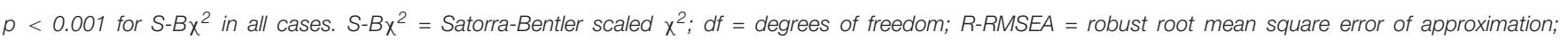
$\mathrm{Cl}$ = confidence interval; SRMR = standardized root mean square residual; $R-C F I=$ robust comparative fit index; $T L I=T$ Tucker Lewis Index.

TABLE 4 | Goodness-of-fit indices for invariance of the trimmed model across gender.

\begin{tabular}{|c|c|c|c|c|c|c|c|c|}
\hline & $x^{2}$ & S-B $\chi^{2}$ & df & TLI & R-CFI & R-RMSEA & SRMR & $\Delta \mathrm{R}-\mathrm{CFI}$ \\
\hline Male & 91026.93 & 72675.50 & 1182 & 0.900 & 0.904 & $0.034[0.034,0.034]$ & 0.049 & \\
\hline Female & 97394.50 & 78792.53 & 1182 & 0.903 & 0.910 & $0.035[0.035,0.035]$ & 0.046 & \\
\hline Model 0 & 188421.42 & 151427.68 & 2364 & 0.900 & 0.907 & $0.024[0.024,0.025]$ & 0.048 & \\
\hline Model 1 & 189471.73 & 152657.94 & 2412 & 0.901 & 0.906 & $0.024[0.024,0.024]$ & 0.049 & -0.001 \\
\hline Model 2 & 189641.89 & 152816.94 & 2415 & 0.901 & 0.906 & $0.024[0.024,0.024]$ & 0.049 & 0.000 \\
\hline Model 3 & 199691.90 & 162146.73 & 2466 & 0.900 & 0.907 & $0.025[0.025,0.025]$ & 0.049 & 0.001 \\
\hline Model 4 & 211280.97 & 170001.21 & 2523 & 0.900 & 0.902 & $0.025[0.025,0.025]$ & 0.051 & -0.005 \\
\hline Model 5 & 200555.12 & 162554.53 & 2502 & 0.901 & 0.906 & $0.025[0.025,0.025]$ & 0.049 & -0.001 \\
\hline
\end{tabular}

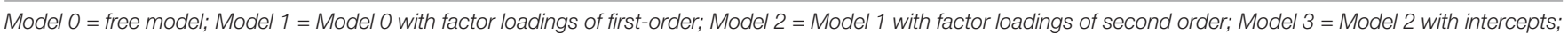

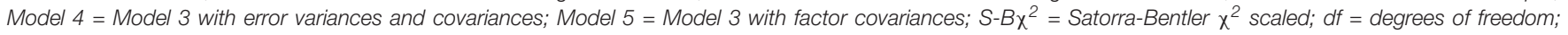

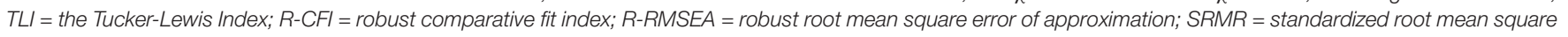
residual; $\triangle R-C F I=$ robust comparative fit index difference test.

$18+$ years $(\mathrm{R}-\mathrm{RMSEA}=0.039,90 \%$ confidence interval: 0.37-0.42; $\mathrm{SRMR}=0.073 ; \mathrm{R}-\mathrm{CFI}=0.891 ; \mathrm{TLI}=0.883)$. Factorial invariance was thus tested for the younger age groups; adequate goodness-of-fit criteria were met and all $\Delta \mathrm{R}$ CFI $>-0.01$ (Table 5). Measurement and structural invariance were thus confirmed.

Regarding invariance across ethnic group, the trimmed model displayed adequate goodness-of-fit criteria for European American, Biracial/Multiracial, Native Hawaiian/Pacific Islander, Hispanic, and American Indian/Alaska Native students (TLI and R-CFI > 0.90; R-RMSEA $<0.05$; SRMR $<0.08$ ) (Table 6). Goodness-of-fit was less strong for African-American (R-RMSEA $=0.034,90 \%$ confidence interval: 0.34-0.35; $\mathrm{SRMR}=0.052 ; \mathrm{R}-\mathrm{CFI}=0.902 ; \mathrm{TLI}=0.894)$ and Asian American (R-RMSEA $=0.036,90 \%$ confidence interval: $0.35-0.36$; SRMR $=0.047 ;$ R-CFI $=0.900 ;$ TLI $=0.888)$ students. Metric invariance was not confirmed (TLI $<0.90$ and SRMR $>0.08$ for Model 2; factorial invariance analyses were thus halted).

\section{DISCUSSION}

The present study examined the adjustment and reliability values of a 9-factor, 66-item measure of school climate and academic mindset among a very large sample of elementary, middle, and high school students. Confirmatory factor analysis supported the proposed factor structure of the School Climate and Academic Mindset Inventory (SCAMI) (i.e., Parent Involvement and Support, Academic Mindset, Social Emotional Learning, Safety, Physical Safety, Bullying, Physical Environment and Resources, Respect for Diversity, and Perceptions of School Performance). Coefficient values were adequate for all subscales (Taber, 2018). Model trimming to arrive at satisfactory goodness-of-fit indices included the removal of items from academic mindset (2 items), social emotional learning (11 items), and perceptions of school environment (2 items). Six other subscales retained their full item integrity and no items shifted from one factor to another. Removed items may constitute supplementary items to be used 
TABLE 5 | Goodness-of-fit indices for invariance of the trimmed model across age.

\begin{tabular}{|c|c|c|c|c|c|c|c|c|}
\hline & $x^{2}$ & S-B $\chi^{2}$ & df & TLI & R-CFI & R-RMSEA & SRMR & $\Delta \mathrm{R}-\mathrm{CFI}$ \\
\hline 9-11 years & 52629.06 & 42181.28 & 1182 & 0.910 & 0.917 & $0.030[0.029,0.030]$ & 0.040 & \\
\hline $12-14$ years & 49769.53 & 40101.60 & 1182 & 0.900 & 0.904 & $0.035[0.035,0.035]$ & 0.046 & \\
\hline Model 0 & 102398.60 & 82288.41 & 2364 & 0.904 & 0.911 & $0.022[0.022,0.023]$ & 0.044 & \\
\hline Model 1 & 103865.77 & 83586.59 & 2412 & 0.905 & 0.910 & $0.022[0.022,0.023]$ & 0.051 & -0.001 \\
\hline Model 2 & 104034.29 & 83732.25 & 2415 & 0.905 & 0.910 & $0.022[0.022,0.023]$ & 0.051 & 0.000 \\
\hline Model 3 & 120179.21 & 97916.29 & 2466 & 0.900 & 0.902 & $0.024[0.024,0.024]$ & 0.053 & -0.008 \\
\hline Model 4 & 128118.79 & 1009211.70 & 2523 & 0.904 & 0.910 & $0.025[0.025,0.025]$ & 0.053 & 0.008 \\
\hline Model 5 & 121071.88 & 98409.56 & 2502 & 0.900 & 0.902 & $0.024[0.024,0.024]$ & 0.051 & 0.000 \\
\hline
\end{tabular}

Model 0 = free model; Model 1 = Model 0 with factor loadings of first-order; Model 2 = Model 1 with factor loadings of second order; Model 3 = Model 2 with intercepts; Model 4 = Model 3 with error variances and covariances; Model $5=$ Model 3 with factor covariances; S-B $\chi^{2}=$ Satorra-Bentler $\chi^{2}$ scaled; $d f=$ degrees of freedom;

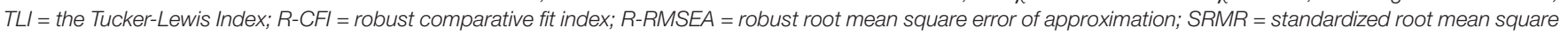
residual; $\triangle R-C F I=$ robust comparative fit index difference test.

TABLE 6 | Goodness-of-fit indices for invariance of the trimmed model across ethnic group.

\begin{tabular}{|c|c|c|c|c|c|c|c|c|}
\hline & $x^{2}$ & S-B $\chi^{2}$ & df & TLI & R-CFI & R-RMSEA & SRMR & $\Delta \mathrm{R}-\mathrm{CFI}$ \\
\hline European American & 56198.61 & 45105.27 & 1182 & 0.902 & 0.909 & $0.036[0.035,0.036]$ & 0.045 & \\
\hline Biracial/Multiracial & 13515.08 & 10854.09 & 1182 & 0.900 & 0.908 & $0.035[0.035,0.036]$ & 0.047 & \\
\hline Native Hawaiian/Pacific Islander & 4401.75 & 3517.27 & 1182 & 0.900 & 0.907 & $0.034[0.033,0.035]$ & 0.054 & \\
\hline Hispanic & 80159.60 & 64407.09 & 1182 & 0.902 & 0.909 & $0.033[0.033,0.034]$ & 0.048 & \\
\hline American Indian/Alaska Native & 2182.76 & 1769.76 & 1182 & 0.911 & 0.917 & $0.034[0.030,0.037]$ & 0.065 & \\
\hline Model 0 & 156457.79 & 125759.75 & 5910 & 0.903 & 0.910 & $0.015[0.015,0.0015]$ & 0.052 & \\
\hline Model 1 & 157851.85 & 127360.183 & 6102 & 0.905 & 0.909 & $0.015[0.015,0.0015]$ & 0.057 & -0.001 \\
\hline Model 2 & 175979.56 & 142085.91 & 6114 & 0.894 & 0.900 & $0.016[0.016,0.0016]$ & 0.082 & -0.009 \\
\hline
\end{tabular}

Model 0 = free model; Model 1 = Model 0 with factor loadings of first-order; Model 2 = Model 1 with factor loadings of second order; S-B ${ }^{2}=$ Satorra-Bentler $\chi^{2}$ scaled; $d f$ = degrees of freedom; TLI = the Tucker-Lewis Index; R-CFI = robust comparative fit index; R-RMSEA = robust root mean square error of approximation; $S R M R=$ standardized root mean square residual; $\Delta R-C F I=$ robust comparative fit index difference test.

with caution. The subscale of Parent Involvement and Support demonstrated lower internal consistency and should also be used with caution.

In addition, the trimmed model displayed adequate goodnessof-fit for males and females, younger age groups, and European American, biracial/multiracial, Hispanic, Native American, and Native Hawaiian/Pacific Islander students. The trimmed model was slightly less strong for older age groups as well as for African American and Asian American students. School climate may be impacted by less social trust in later adolescence as well as differential discrimination among racial groups and percentage of minority students at a given school, which may have affected the results (Flanagan and Stout, 2010; Wang et al., 2014; Wang and Atwal, 2015). Factorial invariance analyses revealed that the SCAMI had an equivalent factor structure by gender and younger age groups. The constructs that the SCAMI is assessing can thus be viewed as comparable between males and females and individuals aged 9-11 and $12-14$ years.

The assessment of school climate continues to evolve, and one advantage of the SCAMI is the inclusion of contextual variables utilized by students in their school-based endeavors, most notably academic mindset and social emotional learning factors. The scale allows researchers and school officials to more compactly study the relationship between various aspects of school climate and these associated variables, which is a burgeoning focus of the climate literature (Allbright et al., 2019).
Researchers, for example, can use the scale in conjunction with grades and standardized test scores to better understand the specific mechanisms by which school climate leads to improved academic achievement (Cornell et al., 2016). In addition, educators and school-based mental health professionals could use the scale to identify schools, classrooms, and even individual students that may require additional support or services to enhance climate and, by extension, academic performance and well-being (Cleveland and Sink, 2017). The scale could be used to identify non-instructional targets of change in an academic environment (Zullig et al., 2010). The SCAMI could also be utilized as part of school climate improvement efforts within the context of multi-tiered systems of support models (James et al., 2018). In these models, Tier 1 system-wide strategies focus heavily on universal or primary prevention practices to promote adaptive behavior and deter maladaptive behavior, often via enhancement of positive school climate, adaptive mindsets, social-emotional competencies, well-managed and engaged classroom behavior, and successful academic performance (Voight and Nation, 2016). The SCAMI can be a practical tool for evaluating many aspects of Tier 1 intervention. In addition, the scale could help districts leverage limited resources by serving as a needs assessment to identify schools most in need of Tier 1 intervention to enhance school climate (Wang and Degol, 2016). This process could occur longitudinally as well to examine patterns of change over time or across grade and developmental levels (László et al., 2019). 
Other tiers in a multi-tiered systems of support model include escalating interventions to address emerging (Tier 2) and later chronic and severe (Tier 3) academic, behavioral, social, and emotional problems (McIntosh and Goodman, 2016). The SCAMI may be utilized to help identify demarcations between these tiers so that schools have better benchmarks for shifting and intensifying the use of resources (Berkowitz, 2019). In addition, the scale may be helpful as part of an algorithm with other known benchmarks such as absenteeism, office discipline referrals, and course grades to help predict long-term outcomes such as school dropout (Kotok et al., 2016; Kearney et al., 2019).

Results from the present study also help confirm the substance of domains commonly ascribed to school climate. Dimensions of school climate are generally considered to be malleable in nature, with little agreement on specific labels among researchers except for wide-ranging relational and safety components (Grazia and Molinari, 2020). Several of the SCAMI school climate subscales can be broadly grouped into relational (parent involvement and support, respect for diversity, perceptions of school performance) and safety (physical safety, bullying) domains. Condition of school facilities, another common element of school climate assessment, is represented as well (Berman et al., 2018). A key advantage of the SCAMI is the presence of multiple items for each of these specific domains.

Limitations of the present study should be noted. First, the measure evaluated here (SCAMI) was derived from a prefabricated survey utilized by the school district involved in the present study. As such, the evaluation of the measure is more data-based than theory-based, and one primary geographical location was involved. In addition, less control was exercised over its distribution, with an unknown number completing the measure at home or school, which may have affected the internal consistency of some of the subscales. Second, the scale was based on student report despite the fact that school climate can affect youth, parents, and teachers, each of whom may evaluate climate differently (Ramsey et al., 2016). Student-based reports and inventories do have advantages, however, including practicality, compliance, and assessment of internalizing variables such as mindset (Yeager et al., 2016). Third, deeper student groupings, such as those with disabilities or mental health problems, were not feasible. Perceptions of school climate may differ among these student groups (La Salle et al., 2018). Finally, the scale was administered only in English; measuring school climate among Spanishspeaking and other-language students should be a future priority (Rocha et al., 2019).

\section{REFERENCES}

Aldridge, J. M., and McChesney, K. (2018). The relationships between school climate and adolescent mental health and wellbeing: a systematic literature review. Int. J. Educ. Res. 88, 121-145. doi: 10.1016/j.ijer.2018.01.012

Allbright, T. N., Marsh, J. A., Kennedy, K. E., Hough, H. J., and McKibben, S. (2019). Social-emotional learning practices: Insights from outlier schools. J. Res. Innovat. Teach. Learn. 12, 35-52. doi: 10.1108/JRIT-02-2019-0020

\section{CONCLUSION}

Despite these limitations, the evaluation of the SCAMI represents one of the largest and most diverse sample sizes with respect to school climate assessment. The results illustrated the adjustment and reliability values of the measure as well as factorial invariance across multiple demographic groups. Future work should focus on expansion of psychometric testing in other geographical regions, further validation, and multilevel modeling to explore individual and collective perceptions of school climate. In addition, the scale's utility for assessing school climate interventions and longitudinal patterns, as well as its value within a multi-tiered systems of support model, should be fully evaluated. Finally, linking findings from the scale to other key school variables such as absenteeism, academic performance, social-emotional competency development, and relational aggression may be instructive.

\section{DATA AVAILABILITY STATEMENT}

The datasets generated for this study are available on request to the corresponding author.

\section{ETHICS STATEMENT}

The studies involving human participants were reviewed and approved by UNLV IRB. Written informed consent from the participants' legal guardian/next of kin was not required to participate in this study in accordance with the national legislation and the institutional requirements.

\section{AUTHOR CONTRIBUTIONS}

All authors revised and approved the submitted version. CK collected the data, wrote the manuscript, and supervised the study. RS and CG performed the analyses and assisted in writing of the manuscript.

\section{FUNDING}

This work was supported by the University of Nevada, Las Vegas. A portion of the publication fees for this article were supported by the UNLV University Libraries Open Article Fund.

Bentler, P. M. (2005). EQS 6.1: Structural equations program manual. Encino, CA: Multivariate Software.

Berkowitz, K. (2019). “The art of integrating school climate initiatives," in Getting more out of restorative practice in schools: Practical approaches to improve school wellbeing and strengthen community engagement, eds M. Thorsborne, N. Riestenberg, and G. McCluskey (London: Jessica Kingsley Publishers), 59-79.

Berkowitz, R., Moore, H., Astor, R. A., and Benbenishty, R. (2017). A research synthesis of the associations between socioeconomic background, inequality, 
school climate, and academic achievement. Rev. Educ. Res. 87, 425-469. doi: $10.3102 / 0034654316669821$

Berman, J. D., McCormack, M. C., Koehler, K. A., Connolly, F., Clemons-Erby, D., Davis, M. F., et al. (2018). School environmental conditions and links to academic performance and absenteeism in urban, mid-Atlantic public schools. Int. J. Hyg. Environ. Health 221, 800-808. doi: 10.1016/j.ijheh.2018.04.015

Bradshaw, C. P., Bottiani, J. H., Osher, D., and Sugai, G. (2014a). "The integration of positive behavioral interventions and supports and social and emotional learning," in Handbook of school mental health, eds M. D. Weist, N. A. Lever, C. P. Bradshaw, and J. S. Owens (New York, NY: Springer), 101-118. doi: 10.1007/978-1-4614-7624-5_8

Bradshaw, C. P., Waasdorp, T. E., Debnam, K. J., and Lindstrom Johnson, S. (2014b). Measuring school climate in high schools: a focus on safety, engagement, and the environment. J. Sch. Health 84, 593-604. doi: 10.1111/josh. 12186

Bradshaw, C. P., Mitchell, M. M., and Leaf, P. J. (2010). Examining the effects of schoolwide positive behavioral interventions and supports on student outcomes: results from a randomized controlled effectiveness trial in elementary schools. J. Posit. Behav. Interv. 12, 133-148. doi: 10.1177/ 1098300709334798

Brown, T. A. (2006). Confirmatory factor analysis for applied research. New York, NY: Guilford.

Byrne, B. M. (2008). Structural equation modeling with EQS: Basic concepts, applications and programing, 2nd Edn. New York, NY: Routledge.

Capp, G., Astor, R. A., and Gilreath, T. D. (2020). Advancing a conceptual and empirical model of school climate for school staff in California. J. Sch. Violence 19, 107-121. doi: 10.1080/15388220.2018.1532298

Cleveland, R. E., and Sink, C. A. (2017). Student happiness, school climate, and school improvement plans: implications for school counseling practice. Prof. School Counseling 21, 1-10. doi: 10.1177/2156759X18761898

Cohen, J., McCabe, L., Michelli, N. M., and Pickeral, T. (2009). School climate: research, policy, practice, and teacher education. Teach. Coll. Rec. 111, 180-213.

Corcoran, R. P., Cheung, A. C., Kim, E., and Xie, C. (2018). Effective universal school-based social and emotional learning programs for improving academic achievement: a systematic review and meta-analysis of 50 years of research. Educ. Res. Rev. 25, 56-72. doi: 10.1016/j.edurev.2017.12.001

Cornell, D., and Huang, F. (2016). Authoritative school climate and high school student risk behavior: a cross-sectional multi-level analysis of student selfreports. J. Youth Adolesc. 45, 2246-2259. doi: 10.1007/s10964-016-0424-3

Cornell, D., Shukla, K., and Konold, T. R. (2016). Authoritative school climate and student academic engagement, grades, and aspirations in middle and high schools. AERA Open 2:2332858416633184. doi: 10.1177/2332858416633184

Darling-Hammond, L., and Cook-Harvey, C. M. (2018). Educating the Whole Child: Improving School Climate to Support Student Success. Palo Alto, CA: Learning Policy Institute.

Durlak, J. A., Domitrovich, C. E., Weissberg, R. P., and Gullotta, T. P. (2015). Handbook of Social and Emotional Learning. New York, NY: Guilford.

Dweck, C. S., Walton, G. M., and Cohen, G. L. (2014). Academic Tenacity: Mindsets and Skills that Promote long-term Learning. Seattle, WA: Bill and Melinda Gates Foundation.

Farrington, C. A., Roderick, M., Allensworth, E., Nagaoka, J., Keyes, T. S., Johnson, D. W., et al. (2012). Teaching Adolescents to Become Learners. the role of Noncognitive Factors in Shaping School Performance: a Critical Literature Review. Chicago, IL: University of Chicago Consortium on Chicago School Research.

Flanagan, C. A., and Stout, M. (2010). Developmental patterns of social trust between early and late adolescence: age and school climate effects. J. Res. Adolesc. 20, 748-773. doi: 10.1111/j.1532-7795.2010.00658.x

Freeman, J., Simonsen, B., McCoach, D. B., Sugai, G., Lombardi, A., and Horner, R. (2016). Relationship between school-wide positive behavior interventions and supports and academic, attendance, and behavior outcomes in high schools. J. Posit. Behav. Interv. 18, 41-51. doi: 10.1177/10983007155 80992

Gage, N. A., Larson, A., and Chafouleas, S. M. (2016). The meriden school climate survey-student version: preliminary evidence of reliability and validity. Assess. Eff. Interv. 41, 67-78. doi: 10.1177/1534508415596960
Gage, N. A., Prykanowski, D. A., and Larson, A. (2014). School climate and bullying victimization: a latent class growth model analysis. Sch. Psychol. Q. 29, 256-271. doi: $10.1037 /$ spq0000064

García-Moya, I., Bunn, F., Jiménez-Iglesias, A., Paniagua, C., and Brooks, F. M. (2019). The conceptualisation of school and teacher connectedness in adolescent research: a scoping review of literature. Educ. Rev. 71, 423-444. doi: 10.1080/00131911.2018.1424117

Gislason, N. (2010). Architectural design and the learning environment: a framework for school design research. Learn. Environ. Res. 13, 127-145. doi: 10.1007/s10984-010-9071-x

Goldstein, S. E., Young, A., and Boyd, C. (2008). Relational aggression at school: associations with school safety and social climate. J. Youth Adolesc. 37, 641-654. doi: 10.1007/s10964-007-9192-4

Gómez-Núñez, M. I., Torregrosa, M. S., Inglés, C. J., Lagos San, Martín, N. G., Sanmartín, R., et al. (2020). Factor invariance of the trait meta-mood scale-24 in a sample of chilean adolescents. J. Pers. Assess. 102, 231-237. doi: 10.1080/ 00223891.2018 .1505730

Gonzálvez, C., Inglés, C. J., Kearney, C. A., Vicent, M., Sanmartín, R., and GarcíaFernández, J. M. (2016). School refusal assessment scale-revised: factorial invariance and latent means differences across gender and age in spanish children. Front. Psychol. 7:1-10. doi: 10.3389/fpsyg.2016.02011

Grazia, V., and Molinari, L. (2020). School climate multidimensionality and measurement: a systematic literature review. Res. Pap. Educ. doi: 10.1080/ 02671522.2019 .1697735

Hanson, J., Bangert, A., and Ruff, W. (2016). Exploring the relationship between school growth mindset and organizational learning variables: implications for multicultural education. J. Educ. Issues 2, 222-243.

Hendron, M., and Kearney, C. A. (2016). School climate and student absenteeism and internalizing and externalizing behavioral problems. Child. Sch. 38, 109116. doi: $10.1093 / \mathrm{cs} / \mathrm{cdw} 009$

Horner, R. H., and Sugai, G. (2015). School-wide PBIS: an example of applied behavior analysis implemented at a scale of social importance. Behav. Anal. Pract. 8, 80-85. doi: 10.1007/s40617-015-0045-4

Hu, I., and Bentler, P. M. (1999). Cut-off criteria for fit indexes in covariance structure analysis: conventional criteria versus new alternatives. Struct. Equ. Model. 6, 1-55. doi: 10.1080/10705519909540118

James, A. G., Smallwood, L., Noltemeyer, A., and Green, J. (2018). Assessing school climate within a PBIS framework: using multi-informant assessment to identify strengths and needs. Educ. Stud. 44, 115-118. doi: 10.1080/03055698.2017. 1347495

Jia, Y., Konold, T. R., and Cornell, D. (2016). Authoritative school climate and high school dropout rates. Sch. Psychol. Q. 31, 289-303. doi: 10.1037/spq0000139

Kearney, C. A., Gonzálvez, C., Graczyk, P. A., and Fornander, M. (2019). Reconciling contemporary approaches to school attendance and school absenteeism: toward promotion and nimble response, global policy review and implementation, and future adaptability (Part 2). Front. Psychol. 10:2605. doi: 10.3389/fpsyg.2019.02605

Kline, R. B. (2005). Principles and Practice of Structural Equation Modeling, 2nd Edn. New York, NY: Guilford.

Konold, T. (2018). A multilevel MTMM approach to estimating the influences of contextual factors on trait and informant-based method effects in assessments of school climate. J. Psychoeduc. Assess. 36, 464-476. doi: 10.1177/ 0734282916683286

Kotok, S., Ikoma, S., and Bodovski, K. (2016). School climate and dropping out of school in the era of accountability. Am. J. Educ. 122, 569-599. doi: 10.1086/ 687275

Kutsyuruba, B., Klinger, D. A., and Hussain, A. (2015). Relationships among school climate, school safety, and student achievement and well-being: a review of the literature. Rev. Educ. 3, 103-135. doi: 10.1002/rev3.3043

La Salle, T. L., George, H. P., McCoach, D. B., Polk, T., and Evanovich, L. L. (2018). An examination of school climate, victimization, and mental health problems among middle school students self-identifying with emotional and behavioral disorders. Behav. Disord. 43, 383-392. doi: 10.1177/0198742918768045

László, K. D., Andersson, F., and Galanti, M. R. (2019). School climate and mental health among swedish adolescents: a multilevel longitudinal study. BMC Public Health 19:1695. doi: 10.1186/s12889-019-8018-0 
Lawson, G. M., McKenzie, M. E., Becker, K. D., Selby, L., and Hoover, S. A. (2019). The core components of evidence-based social emotional learning programs. Prev, Sci. 20, 457-467. doi: 10.1007/s11121-018-0953-y

Lee, E., Reynolds, K. J., Subasic, E., Bromhead, D., Lin, H., Marinov, V., et al. (2017). Development of a dual school climate and school identification measurestudent (SCASIM-St). Contemp. Educ. Psychol. 49, 91-106. doi: 10.1016/j. cedpsych.2017.01.003

Lee, J., and Shute, V. J. (2010). Personal and social-contextual factors in K-12 academic performance: an integrative perspective on student learning. Educ. Psychol. 45, 185-202. doi: 10.1080/00461520.2010.493471

Leung, D. Y., Wong, E. M., Chan, S. S., and Lam, T. H. (2013). Psychometric properties of the Big Five Inventory in a Chinese sample of smokers receiving cessation treatment: a validation study. J. Nurs. Educ. Pract. 3, 1-10. doi: 10. 5430/jnep.v3n6p1

Lewis, T. J., McIntosh, K., Simonsen, B., Mitchell, B. S., and Hatton, H. L. (2017). Schoolwide systems of positive behavior support: implications for students at risk and with emotional/behavioral disorders. AERA Open 3:2332858417711428. doi: 10.1177/2332858417711428

Lindstrom Johnson, S., Reichenberg, R. E., Shukla, K., Waasdorp, T. E., and Bradshaw, C. P. (2019). Improving the measurement of school climate using item response theory. Educ. Meas. Issues Pract. 38, 99-107. doi: 10.1111/emip. 12296

Maxwell, S., Reynolds, K. J., Lee, E., Subasic, E., and Bromhead, D. (2017). The impact of school climate and school identification on academic achievement: multilevel modeling with student and teacher data. Front. Psychol. 8:2069. doi: 10.3389/fpsyg.2017.02069

McDonald, R. P. (1999). Test Theory: a Unified Treatment. Mahwah, NJ: Erlbaum.

McIntosh, K., and Goodman, S. (2016). Integrated Multi-tiered Systems of support: Blending RTI and PBIS. New York, NY: Guilford.

McMillan, J. H., Shakeshaft, C., and Hutton, A. C. (2017). School Climate Development Survey. Richmond, VA: Metropolitan Educational Research Consortium.

Olsen, J., Preston, A. I., Algozzine, B., Algozzine, K., and Cusumano, D. (2018). A review and analysis of selected school climate measures. Clear. House: J. Educ. Strateg. Issues Ideas 91, 47-58. doi: 10.1080/00098655.2017.1385999

Ramelow, D., Currie, D., and Felder-Puig, R. (2015). The assessment of school climate: review and appraisal of published student-report measures. J. Psychoeduc. Assess. 33, 731-743. doi: 10.1177/0734282915584852

Ramsey, C. M., Spira, A. P., Parisi, J. M., and Rebok, G. W. (2016). School climate: perceptual differences between students, parents, and school staff. Sch. Eff. Sch. Improv. 27, 629-641. doi: 10.1080/09243453.2016.1199436

Rattan, A., Savani, K., Chugh, D., and Dweck, C. S. (2015). Leveraging mindsets to promote academic achievement: policy recommendations. Perspect. Psychol. Sci. 10, 721-726. doi: 10.1177/1745691615599383

Reaves, S., McMahon, S. D., Duffy, S. N., and Ruiz, L. (2018). The test of time: a meta-analytic review of the relation between school climate and problem behavior. Aggress. Violent Behav. 39, 100-108. doi: 10.1016/j.avb.2018.01.006

Rocha, L., Lenz, A. S., and Aras, Y. (2019). Measuring school climate among Spanish-speaking students: a systematic review of primary methodological studies. Hisp. J. Behav. Sci. 41, 464-480. doi: 10.1177/0739986319880224

Rudasill, K. M., Snyder, K. E., Levinson, H., and Adelson, J. L. (2018). Systems view of school climate: a theoretical framework for research. Educ. Psychol. Rev. 30, 35-60. doi: 10.1007/s10648-017-9401-y

Shukla, K. D., Waasdorp, T. E., Lindstrom Johnson, S., Orozco Solis, M. G., Nguyen, A. J., Rodríguez, C. C., et al. (2019). Does school climate mean the same thing in the United States as in Mexico? a focus on measurement invariance. J. Psychoeduc. Assess. 37, 55-68. doi: 10.1177/0734282917731459

Sugai, G., and Horner, R. (2002). The evolution of discipline practices: school-wide positive behavior supports. Child. Fam. Behav. Ther. 24, 23-50. doi: 10.1300/ J019v24n01-03
Taber, K. S. (2018). The use of Cronbach's alpha when developing and reporting research instruments in science education. Res. Sci. Ed. 48, 1273-1296. doi: 10.1007/s11165-016-9602-2

Thapa, A., and Cohen, J. (2017). School climate community scale: report on construct validity and internal consistency. Sch. Comm. J. 7, 303-320.

Thapa, A., Cohen, J., Guffey, S., and Higgins-D'Alessandro, A. (2013). A review of school climate research. Rev. Educ. Res. 83, 357-385. doi: 10.3102/ 0034654313483907

Thomas, K. J., Moreira, de Cunha, J., Americo, de Souza, D., and Santo, J. (2019). Fairness, trust, and school climate as foundational to growth mindset: a study among Brazilian children and adolescents. Educ. Psychol. 39, 510-529. doi: 10.1080/01443410.2018.1549726

Uline, C. L., Wolsey, T. D., Tschannen-Moran, M., and Lin, C. D. (2010). Improving the physical and social environment of school: a question of equity. J. Sch. Leadersh. 20, 597-632. doi: 10.1177/105268461002000504

Vilagut, G., Ferrer, M., Rajmil, L., Rebollo, P., Permanyer-Miralda, G., Quintana, J. M., et al. (2005). El cuestionario de salud SF-36 español: una década de experiencia y nuevos desarrollos [The Spanish version of the Short Form 36 health survey: a decade of experience and new developments]. Gac. Sanit. 19, 135-150. doi: 10.1157/13074369

Voight, A., and Nation, M. (2016). Practices for improving secondary school climate: a systematic review of the research literature. Am. J. Community Psychol. 58, 174-191. doi: 10.1002/ajcp.12074

Wang, C., and Atwal, K. (2015). School climate, discrimination, and depressive symptoms among Asian American adolescents. Contemp. Sch. Psychol. 19, 205-217. doi: 10.1007/s40688-014-0040-8

Wang, M. T., and Degol, J. L. (2016). School climate: a review of the construct, measurement, and impact on student outcomes. Educ. Psychol. Rev. 28, 315352. doi: 10.1007/s10648-015-9319-1

Wang, W., Vaillancourt, T., Brittain, H. L., McDougall, P., Krygsman, A., Smith, D., et al. (2014). School climate, peer victimization, and academic achievement: results from a multi-informant study. Sch. Psychol. Quart. 29, 360-377. doi: $10.1037 /$ spq0000084

Yeager, D. S., and Dweck, C. S. (2012). Mindsets that promote resilience: when students believe that personal characteristics can be developed. Educ. Psychol. 47, 302-314. doi: 10.1080/00461520.2012.722805

Yeager, D. S., Romero, C., Paunesku, D., Hulleman, C. S., Schneider, B., Hinojosa, C., et al. (2016). Using design thinking to improve psychological interventions: the case of the growth mindset during the transition to high school. J. Educ. Psychol. 108, 374-391. doi: 10.1037/edu000 0098

Zullig, K. J., Koopman, T. M., Patton, J. M., and Ubbes, V. A. (2010). School climate: historical review, instrument development, and school assessment. J. Psychoeduc. Assess. 28, 139-152. doi: 10.1177/07342829093 44205

Zullig, K. J., Ward, R. M., Huebner, E. S., and Daily, S. M. (2018). Association between adolescent school climate and perceived quality of life. Child Indic. Res. 11, 1737-1753. doi: 10.1007/s12187-0179521-4

Conflict of Interest: The authors declare that the research was conducted in the absence of any commercial or financial relationships that could be construed as a potential conflict of interest.

Copyright (c) 2020 Kearney, Sanmartín and Gonzálvez. This is an open-access article distributed under the terms of the Creative Commons Attribution License (CC BY). The use, distribution or reproduction in other forums is permitted, provided the original author(s) and the copyright owner(s) are credited and that the original publication in this journal is cited, in accordance with accepted academic practice. No use, distribution or reproduction is permitted which does not comply with these terms. 